\title{
CMS Announces New Payment Model
}

On Tuesday, 1/9/18, the Centers for Medicare and Medicaid (CMS) announced a new voluntary bundled-payment model that will be considered an advanced alternative payment model under Medicare Access and CHIP Reauthorization Act of 2015 (MACRA) (1). The new model is the first advanced Alternative Payment Model (APM) to be introduced by the Trump administration. The Trump administration has been a vocal advocate of reducing administrative burden for clinicians and has touted voluntary models as a solution (2). The new, voluntary model comes less than two months after the CMS officially decided to eliminate two mandatory bundled-payment models created during the Obama administration.

Under the model, clinician payment will be based on quality measures during a 90-day episode of care. Participants must select at least one of the 32 clinical episodes to apply to the model. The inpatient clinical episodes are listed in Table 1.

Table 1. Clinical inpatient episodes under proposed payment model.

- Acute myocardial infarction

- Back \& neck except spinal fusion

- Cardiac arrhythmia

- Cardiac defibrillator

- Cardiac valve

- Cellulitis

- Cervical spinal fusion

- COPD, bronchitis, asthma

- Combined anterior posterior spinal fusion

- Congestive heart failure

- Coronary artery bypass graft

- Double joint replacement of the lower extremity

- Fractures of the femur and hip or pelvis

- Gastrointestinal hemorrhage

- Gastrointestinal obstruction

- Hip \& femur procedures except major joint

- Lower extremity/humerus procedure except hip, foot, femur

- Major bowel procedure

- Major joint replacement of the lower extremity

- Major joint replacement of the upper extremity

- Pacemaker

- Percutaneous coronary intervention

- Renal failure

- Sepsis

- Simple pneumonia and respiratory infections

- Spinal fusion (non-cervical) 
- Stroke

- Urinary tract infection

Providers will be eligible for bonuses based on their performance. For more information about the model and its requirements, or to download a Request for Applications document (RFA), the application template, and the necessary attachments, please visit: https://innovation.cms.gov/initiatives/bpci-advanced. Applications must be submitted via the Application Portal, which will close on 11:59 pm EST on March 12, 2018. Applications submitted via email will not be accepted.

The CMS Innovation Center will hold a Q\&A Open Forum on Tuesday, January 30, 2018 from $12 \mathrm{pm}-1 \mathrm{pm}$ EDT. This event is open to those who are interested in learning more about the model and how to apply. Please register in advance here - https://preaward.adobeconnect.com/e3cdwg6hgx9f/event/registration.html.

Richard A. Robbins, MD

Editor, SWJPCC

\section{References}

1. Centers for Medicare and Medicaid Services. CMS announces new payment model to improve quality, coordination, and cost-effectiveness for both inpatient and outpatient care. January 9, 2018. Available at: https://www.cms.gov/Newsroom/MediaReleaseDatabase/Pressreleases/2018-Press-releases-items/2018-01-09.html (accessed 1/10/18).

2. Castellucci M. CMS launches new voluntary bundled-payment model. Modern Healthcare. January 9, 2018. http://www.modernhealthcare.com/article/20180109/NEWS/180109905 (accessed 1/10/18).

3. Centers for Medicare and Medicaid Services. BPCI Advanced. January 9, 2018. Available at: https://innovation.cms.gov/initiatives/bpci-advanced (accessed 1/10/18). 